Accepted refereed manuscript of:

Crispin V, Bugge C \& Stoddart K (2017) Sufficiency and relevance of information for inpatients in general ward settings: a qualitative exploration of information exchange between patients and nurses, International Journal of Nursing Studies, 75, pp. 112-122.

DOI: $10.1016 /$ j.ijnurstu.2017.07.010

(C) 2017, Elsevier. Licensed under the Creative Commons AttributionNonCommercial-NoDerivatives 4.0 International http://creativecommons.org/licenses/by-nc-nd/4.0/ 


\section{Title}

Sufficiency and relevance of information for inpatients in general ward settings: a qualitative exploration of information exchange between patients and nurses.

\section{Authors' names and affiliations}

Dr Vivianne Crispin a 1

Dr Carol Bugge a

Dr Kathleen Stoddart a

a University of Stirling, Bridge of Allan, Stirling, Scotland, UK, FK9 4LA

${ }^{1}$ University of the West of Scotland, Hamilton, Scotland, UK, ML3 0JB

\section{Corresponding author}

Dr Vivianne Crispin PhD., Lecturer in Adult Nursing, School of Health, Nursing and Midwifery, University of the West of Scotland, Hamilton, Scotland, UK, ML3 OJB

Tel: +44 1698283100 Ext 8674

Email address: vivianne.crispin@uws.ac.uk

Accepted for publication in International Journal of Nursing Studies by Elsevier. The original publication can be found at: https://doi.org/10.1016/j.jinurstu.2017.07.010 


\title{
Sufficiency and relevance of information for inpatients in general ward settings: a qualitative exploration of information exchange between patients and nurses.
}

\begin{abstract}
Background: Information exchange as part of shared decision-making is widely discussed in research and policy literature as a means of improving patient involvement in treatment and care. To date information exchange between patients and nurses has not been explored in ward contexts.

Objective: To explore the sufficiency of, and intentions behind, information exchanged by patients and nurses in surgical and medical ward settings using a recognised model of shared decision-making.

Design: A multiple-case study design was used. Data were collected from 19 cases. Each case comprised one patient, the nurses interacting with that patient, the interactions between them, and their perceptions about the interactions.

Settings: The study was undertaken across six surgical, six medical and one rehabilitation ward in a large teaching hospital in the United Kingdom.

Participants: Purposive sampling was used to first recruit nurses and then patients. Inclusion criteria included nurses registered with the Nursing and Midwifery Council, and patients who had been in hospital for more than 24 hours and who could consent to participating. Twenty-two nurses and 19 patients participated.

Methods: Interactions from 19 cases were observed and audio-recorded. Individual interviews with patients and nurses followed, and were related to, the observed interactions.

Results: Patients and nurses perceived they had exchanged sufficient information for their own needs including patient involvement, due to: information being shared previously and on an ongoing basis; having asked all their questions; therapeutic patient/nurse relationships; and, nurses speaking in lay terms. In contrast, the observational data suggested that insufficient information was exchanged between patients and nurses due to: lost opportunities for sharing information; paternalistic practice; and withholding information.

Conclusion: The elements of information exchange within a recognised model of shared decision-making do not adequately fit with patient/nurse interactions in ward settings. Participants generally perceived they had given and received enough information for their own needs. Therefore, the ways in which patients and nurses currently interact, could remain as they are. Policymakers should be aware of the varying contexts where healthcare staff work, and should promote information exchange and shared decision-making more strategically. Due to the complexities of patient/nurse interactions, consideration should be given to situation and context when applying these findings to practice.

Keywords: Information exchange; multiple-case study design; observational research; patient/nurse interactions; shared decision-making.
\end{abstract}




\section{Introduction}

Information exchange is important for shared decision-making and has been explored globally in general practitioner (GP) settings (Edwards and Elwyn 2004; van den Brink-Muinen et al, 2006), acute care settings, for example in clinics and emergency care (Bugge et al. 2006; Entwistle et al. 2006; Isaacs et al. 2013), and in caring for patients with chronic conditions (Nelson et al. 2005; Shortus et al. 2013).These studies consistently find that the information patients want is not the information they receive. Despite policy rhetoric on shared decision-making and information exchange applying to all areas of healthcare, little is known about information exchange between patients and nurses during routine nursing care in general ward settings.

Shared decision-making in healthcare incorporates information exchange (Charles et al. 1999). The Charles et al. (1999) model of shared decision-making has information exchange as one of its components. The model illustrates that information exchange comprises: information flow; two-way dialogue; type of information shared; and, amount or sufficiency of information shared. During information exchange patients and health professionals share their values, beliefs and lay knowledge, or their expertise and resources, respectively. Charles et al. (1999) state that for shared decision-making to occur the amount of information exchanged should be all that is required for decision-making, or for any other patient and/or professional needs.

An extensive search was undertaken in the following databases: CINAHL; Health Source: Nursing/Academic Edition; Applied Social Sciences Index and Abstracts; Social Services Abstracts; Sociological Abstracts; and Social Sciences Citation Index. Search terms included: "informed consent AND nurs* OR health profession*"; "information exchange AND patient"; "information exchange AND nurs*"; "informed consent AND decision making"; "informed consent AND decision making AND patient"; and "information exchange AND patient AND nursing care". However, these searches resulted in no literature being identified on information exchange between patients and nurses in ward settings. A further search in the nursing literature on patients' information needs revealed a focus on information provision, the one-way transfer of information from nurses to patients (Jacobs 2000; Logan et al. 2008; May et al. 2006; Suhonen and Leino-Kilpi 2006).

One aspect of information exchange which has seldom been explored is whether or not patients and health professionals give and receive sufficient information. Sufficiency of information has been linked to improved patient involvement in decision-making about treatment and care, and improved health outcomes (Duncan et al. 2010; Joosten et al. 2008), consequently, there is an urgent need for further research in this area (Duncan et al. 2010). Patients have mixed views on information sufficiency with some British and Scandinavian patients expressing that they received insufficient information (Doherty and Doherty 2005; Suhonen et al. 2005) whilst others reporting that they receive too much information (Doherty and Doherty 2005). Standardised patient information in Swedish hospitals resulted from surgical patients' information needs being used to develop information resources (Lithner and Zilling 2000), rather than for determining whether or not patients receive sufficient information.

Good quality research on information exchange between patients and nurses in ward-based settings, and whether or not they receive sufficient information, is lacking. This is important because research in other contexts has demonstrated that 
receiving sufficient information encourages patient involvement in their treatment and care, and can lead to positive healthcare outcomes. Information exchange is related to the type of information, two-way flow of information, and the amount or sufficiency of information. This paper reports on the sufficiency of information exchanged in patient/nurse interactions in general ward settings, during routine nursing care.

\section{The study}

\subsection{Aim and definitions}

Data are derived from a project (Crispin et al. (unpublished results)) that aimed to explore the type, the intentions, and the sufficiency of information exchanged in interactions between patients and nurses in general ward settings. Data related to sufficiency, and some of the intentions behind information exchange are reported here.

Routine nursing care for this study is defined as individualised physical, psychological and informational care that promotes safety and comfort, and is based on Nursing Minimum Data Sets. Nursing Minimum Data Sets include meeting basic nursing care needs, controlling pain, monitoring vital signs, administering medication, pressure area care, wound care, and caring for tubes, drains and catheters (Butler et al. 2006; Goossen et al. 2000; Werley et al. 1991). Routine nursing care relates to physical, psychological, and educational needs, problem-solving, and advocating for patients (Butler et al. 2006). Thus any opportunity that nurses have to share information with patients can be regarded as routine nursing care, or arguably 'fundamentals of care' (Francis 2013), expected of every registered nurse. These 'fundamentals of care' may differ in the complexity of nursing interventions, and may range from general 'chit-chat' to more involved patient/nurse interactions. They are also considered relevant for exploring information exchange, and whether or not patients and nurses receive sufficient information.

\subsection{Design}

A qualitative multiple-case study design, using non-participant observations and semi-structured face-to-face interviews was used to describe the complex social phenomena of information exchange (Yin 2014). Each case comprised a patient, the nurses caring for that patient, and the interactions between them.

\subsection{Participants}

Data were gathered in an urban-based hospital in the United Kingdom (UK). The setting comprised surgical, medical and rehabilitation overnight stay wards, which admitted adult male and female patients. Registered nurses received information about the study, addressed to them and sent to the ward where they currently worked. Group meetings about the study were then held on the wards and nurses interested in taking part were asked to sign a consent form. Qualified nurses ranging from newly qualified to those responsible for recruitment and retention of staff, were eligible if they were fluent in English. Nurses were recruited first as the more consenting nurses there were in the study, the easier it would be to match nurses with consenting patients, being cognisant of nurses' holidays, days off and any periods of illness. A purposive sample of nurses were recruited, reflecting qualified registered nurses at different stages in their career, and a mix of female and male nurses. 
A purposive maximum variation sample of patients was recruited (Cresswell 2013). The sample was chosen to reflect multiple perspectives about information exchange. For example, patients were chosen from surgical, medical and rehabilitation wards in order to gain varying perspectives from patients receiving surgery, and patients who are experiencing long-term, and potentially life-limiting chronic conditions. Nurses gave patients an information sheet that explained the study. Nurses informed the researcher if patients were interested in taking part. Discussions between each interested patient and the researcher took place. The study was explained in detail, and patients' questions were answered. Patients who wanted to participate signed a consent form. Patients eighteen years of age or over, and fluent in English, were included. Patients were only included if a nurse who had consented to take part in the study was on duty. Patients were excluded if they were within twenty-four hours of receiving sedation or an anaesthetic.

\section{Data collection}

Data were collected by VC over seven months, using audio-recorded semistructured observations of the interactions between patients and nurses during routine nursing care. A semi-structured schedule was used to guide the observational data collection. Recordings took place when a consenting nurse interacted with a consenting patient. Each observation session lasted ninety minutes, during which the audio equipment was remotely accessed using a new data collection method. An innovative remote audio-recording method was used to ensure that consenting patients could freely converse with other patients and health professionals without being recorded. As the data collection method was new, it was piloted to ensure satisfactory operation and acceptability for patients and nurses. The recording equipment comprised a small radio-microphone, a radio receiver box and a digital recorder. The radio-controlled microphone was placed near the patient, usually on the bedside table or the patient's locker. The microphone was not 'attached' to the patients or the nurses. The researcher sat further away from the patient, often outside of the patient's room, with the digital recorder plugged into the radio receiver box. The receiver box was switched on and off as required capturing only consenting patient/nurse interactions. Field notes were taken on an ad hoc basis throughout the ninety-minute observation sessions. The recording system allowed for sitting outside of patients' rooms if required, whilst still being able to hear the interactions. Some four-bedded rooms had glass panels through which the researcher could observe the interactions. Each patient/nurse interaction was audiorecorded. As a nurse, there was the possibility that the researcher could influence the research findings. Writing about the significance of any influence in a reflexive journal, helped keep that influence to a minimum. Field notes included: information about the environment; points that were important about the interactions; notes about claims that could be made from the interactions; length and topics of each interaction; ideas that could be followed up at interview; and ideas that might help in data collection with future cases.

Following the observations, and on the same day, semi-structured face-toface audio-recorded interviews, about the observed interactions, were conducted with patients and nurses individually. Interviews lasted between 20 and 35 minutes. Nurse interviews were conducted in an office on the ward. Most patients chose to be interviewed at their bedside with the curtain drawn. One patient preferred to be interviewed in an office on the ward. Interview schedules based on features of the 
observed interactions, were used to guide the interviews. A pilot study tested whether the interviews should come immediately after the observations, or if it was best to take time after the observations to write up field notes including questions that could explore the type, intentions and sufficiency of information further. From the pilot study it was found to be more beneficial to the researcher and the nurses to take a short period of time to review the observations before proceeding to interview. Participants were free to talk about their experiences and perceptions, however the interview was guided by questions such as, "How do you know when you have had enough information?", or, "How would you define 'enough' information?" The interview data were used to clarify and add to the observation data. The observations and interviews continued until data saturation had been reached. At the point of data saturation none of the participants were saying anything that had not already been added to existing concepts important for this study (Holloway and Wheeler 2010).

Triangulation, using observations and interviews, was used for completeness (Fielding and Fielding 1986; Shih 1998; Yin 2014) in order to capture varied, and even conflicting, data, giving more depth to the analysis (Jones and Bugge 2006).

\subsection{Ethical considerations}

All participants received a letter of invitation and an information sheet, which included the researcher's contact details and the contact details of someone independent of the study. Informed consent was obtained by the researcher prior to data collection. Ethical approval was obtained from the National Health Service Research Ethics Service via the Integrated Research Application System. Participants consented to: their interactions being observed; being interviewed; their interactions and interviews being audio-recorded and transcribed by the researcher; their audio-recorded and transcribed data being kept in a secure place; and their anonymised data being disseminated. Participants understood that they could withdraw from the study at any time, and without having to provide an explanation.

\subsection{Data analysis}

The iterative analytical process drew on methods of data reduction, data display, and verification and conclusion drawing (Miles et al. 2013), and was developed over six stages: initial annotation; data transcription; data reduction (1); data reduction (2); data display; and, conclusion drawing and verification. These stages are presented in Figure 1. The analytical process helped to focus the data and organise it into an accessible form. Case summaries detailed the demographics of the participants, the interactions and interviews, the chronic or acute condition of patients, the number of days each patient had been in hospital, the experience of the nurse, the number of years the nurses were post-qualification, the number of years the nurses had worked in their current ward, and any other background factors. A systematic approach was taken to analyse the data, which began early during data collection. Time was spent away from the ward looking over the initial field notes of each observation session, reflecting on the patient/nurse interaction and formulating additional questions for the semi-structured interview sessions later that day. The analytical strategy fitted into a combination of relying on theoretical propositions, and working with the data from the ground up. In other words, a priori codes were taken from what is known about the Charles et al. (1999) model of information exchange, which for this paper is information related to the amount of information. However, as 
well as using the theory of information exchange for shared decision making to critique practice, inductive codes were developed directly from the observation and interview data, which allowed for using data to test the theory.

\section{Figure 1: Six stages of data analysis}

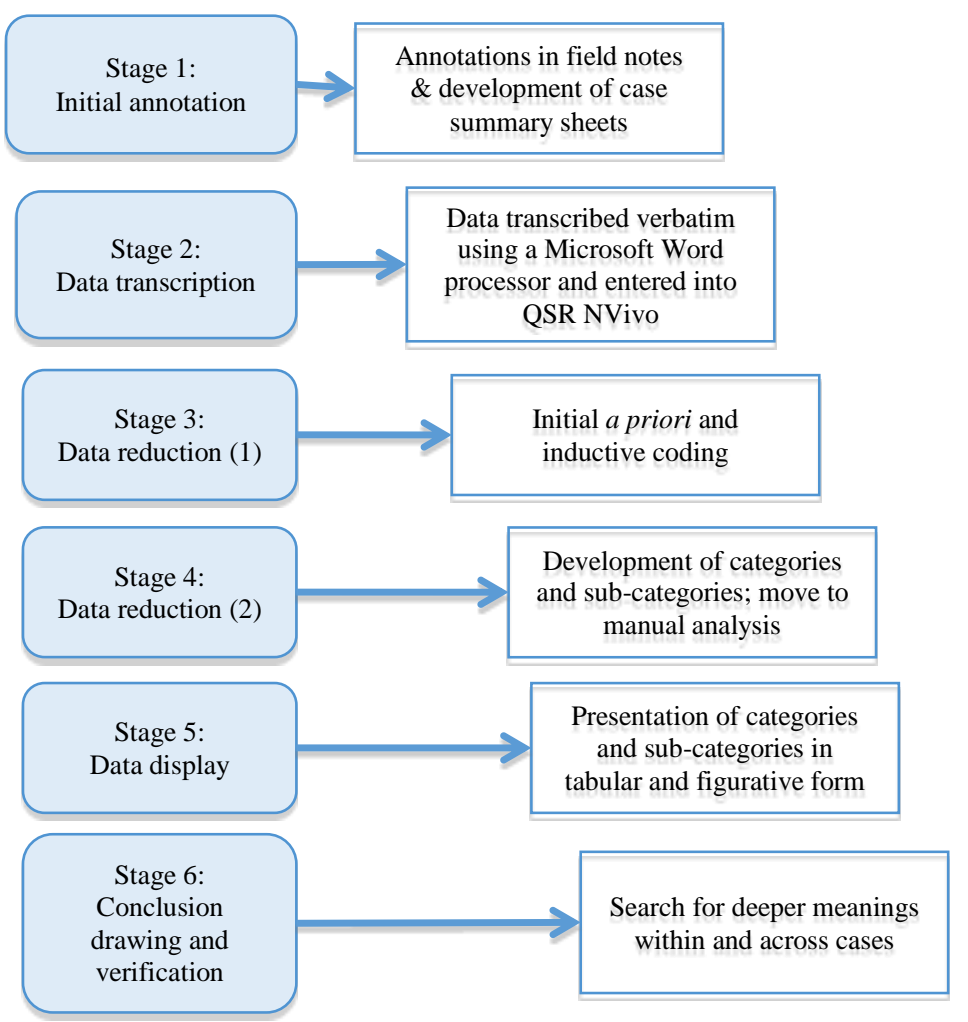

Data from recorded interactions, field notes and interviews were transcribed verbatim and managed in QSR NVivo 10. After transcription these data were pored over line by line applying both a priori codes and inductive codes to each section of the data. These codes were grouped together creating 'trees' within the software, which represented categories and subcategories. Analysis was undertaken initially on a case by case basis. Categories and subcategories related to the amount of information that was observed to have been exchanged or provided, between participants. Categories and sub-categories also related to participants' perspectives on whether or not the information exchanged was sufficient for their needs. These categories and subcategories were initially explored within the individual cases. Patterns, similarities and differences within, and across, cases, were then searched for and explained.

\section{Results}

\subsection{Participants}

Twenty-one patients wanted to take part, however, two patients were unable to participate as they felt unwell on the day of data collection. In total, nineteen patients and twenty-two nurses, from one rehabilitation ward, six surgical and six medical wards, participated in the study. Patient and nurse characteristics are presented in Tables 1 and 2, respectively. All participants were given a pseudonym in accordance with the Data Protection Act (1998).

Crispin et al. (2016) 
Table 1: Patients' characteristics

\begin{tabular}{|c|c|c|c|c|c|c|}
\hline Pseudonym & Ward & Gender & Age & Previous admissions & Reason for this admission & $\begin{array}{l}\text { Post-op days } \\
\text { (if app) }\end{array}$ \\
\hline Alice & Urology & Female & 28 & Surgery to slow down growth & $\begin{array}{l}\text { Pyelonephritis } \\
\text { Stones \& cyst in kidney. }\end{array}$ & N/A \\
\hline Barry & Surgical receiving & Male & 23 & Surgery to hand & Non-accidental wound & 1 \\
\hline Colin & Colorectal & Male & 64 & Pancreatic problems & $\begin{array}{l}\text { Formation of stoma related to problems with } \\
\text { pancreas }\end{array}$ & $\begin{array}{l}6-7 \text { wks ago - patien } \\
\text { unable to remember }\end{array}$ \\
\hline Donald & Urology & Male & 69 & Peri-anal abscess; vasectomy repair & Transurethral resection of prostate (TURP) & 3 \\
\hline Eddie & Vascular & Male & & Surgery to hand due to nerve damage & Above knee amputation & 10 \\
\hline Fred & Surgical receiving & Male & 59 & & Pancreatitis & N/A \\
\hline Grace & Surgical receiving & Female & 57 & $\begin{array}{l}\text { Gallbladder surgery; seven admissions since with } \\
\text { sepsis }\end{array}$ & Sepsis & N/A \\
\hline Harriet & Coronary care & Female & 81 & COPD; Stroke & Exacerbation of COPD & N/A \\
\hline Iris & $\begin{array}{l}\text { Upper GI, hepatobiliary \& } \\
\text { pancreatic unit }\end{array}$ & Female & 55 & Childbirth; spinal injuries; fibroids; hysterectomy & Surgery to repair burst bowel after hysterectomy & 7wks ago \\
\hline Jack & Urology & Male & 62 & $\begin{array}{l}\text { Tonsillectomy; hernia repair; gall bladder removal; } \\
\text { parotid gland surgery; cartilage repair to right knee }\end{array}$ & Transurethral resection of prostate (TURP) & 1 \\
\hline Kirsty & Coronary care & Female & 69 & $\begin{array}{l}\text { Tonsillectomy; appendectomy; rheumatic fever; } \\
\text { mitral valve replacement; gastro-intestinal bleed \& } \\
\text { septicaemia; surgery for twisted bowel; aorta repair }\end{array}$ & Insertion of pacemaker & 4 \\
\hline Larry & $\begin{array}{l}\text { Male general medicine, } \\
\text { cardiology \& diabetes }\end{array}$ & Male & 74 & Gall stone removal; heart attack; chest pain & Chest pain & N/A \\
\hline Mark & Male respiratory medicine & Male & 69 & Breathlessness; chest infections & Chest infection & N/A \\
\hline Neil & Male respiratory medicine & Male & 53 & $\begin{array}{l}\text { Diabetes; blood clots; heart attacks; bleeding from } \\
\text { varices, tracheostomy insertion }\end{array}$ & Infection around tracheostomy site & N/A \\
\hline Olive & $\begin{array}{l}\text { Female general medicine, } \\
\text { cardiology \& diabetes }\end{array}$ & Female & 59 & COPD; diabetes; atrial fibrillation & Chest pain; chest infection; kidney failure & N/A \\
\hline Peter & $\begin{array}{l}\text { Male general medicine, } \\
\text { cardiology \& diabetes }\end{array}$ & Male & 50 & Gastroenteritis, pancreatitis & Viral infection in kidneys & N/A \\
\hline Rose & Female general medicine & Female & 47 & $\begin{array}{l}\text { Growth in breast; hysterectomy; gall bladder } \\
\text { removal; ectopic pregnancy }\end{array}$ & Dizziness and headaches & N/A \\
\hline Steve & Orthopaedic & Male & 33 & Appendectomy & Wound washout due to infection & 7 wks ago \\
\hline Tracy & Orthopaedic rehabilitation & Female & 41 & $\begin{array}{l}\text { Discoloured right foot - diagnosed with diabetes; } \\
\text { dislocated and fractured left ankle }\end{array}$ & Above knee amputation & 8 \\
\hline
\end{tabular}

Crispin et al. (2016)

Page 8 of $\mathbf{2 5}$ 
Table 2: Nurses' characteristics

\begin{tabular}{|c|c|c|c|c|c|}
\hline Ward & Gender & Pseudonym & Position & $\begin{array}{l}\text { No. of years' } \\
\text { experience }\end{array}$ & $\begin{array}{l}\text { Time in current } \\
\text { place of work }\end{array}$ \\
\hline Surgical receiving & Female & Ann & $\begin{array}{l}\text { Registered staff } \\
\text { nurse }\end{array}$ & 9 & 9 years \\
\hline Urology & Female & Cathy & $\begin{array}{l}\text { Registered staff } \\
\text { nurse }\end{array}$ & 2 & 2 years \\
\hline Surgical receiving & Male & Duncan & $\begin{array}{l}\text { Registered staff } \\
\text { nurse }\end{array}$ & 27 & 4 years \\
\hline Urology & Female & Helen & $\begin{array}{l}\text { Registered staff } \\
\text { nurse }\end{array}$ & 10 & $1 \frac{1}{2}$ years \\
\hline Urology & Female & Ivy & $\begin{array}{l}\text { Registered staff } \\
\text { nurse }\end{array}$ & 10 months & 10 months \\
\hline Urology & Female & Kate & $\begin{array}{l}\text { Registered staff } \\
\text { nurse }\end{array}$ & 6 & 2 years \\
\hline Upper GI, hepato-biliary \& pancreatic unit & Female & Lesley & $\begin{array}{l}\text { Registered nurse } \\
\text { in charge }\end{array}$ & 29 & 7 years \\
\hline Upper GI, hepato-biliary \& pancreatic unit & Male & Oliver & $\begin{array}{l}\text { Registered staff } \\
\text { nurse }\end{array}$ & 1 & 1 years \\
\hline Colorectal & Female & Queenie & $\begin{array}{l}\text { Registered staff } \\
\text { nurse }\end{array}$ & 11 & 10 years \\
\hline Orthopaedic rehabilitation & Female & Una & $\begin{array}{l}\text { Registered staff } \\
\text { nurse }\end{array}$ & 28 & $11 / 2$ years \\
\hline Acute orthopaedics & Female & Wendy & $\begin{array}{l}\text { Registered staff } \\
\text { nurse }\end{array}$ & 4 & 4 years \\
\hline Acute orthopaedics & Female & Xena & $\begin{array}{l}\text { Registered nurse } \\
\text { in charge }\end{array}$ & 7 & 3 years \\
\hline Colorectal & Female & Yvonne & $\begin{array}{l}\text { Registered staff } \\
\text { nurse }\end{array}$ & 4 & 4 years \\
\hline Coronary care & Female & Carol & $\begin{array}{l}\text { Registered nurse } \\
\text { in charge }\end{array}$ & 28 & 23 years \\
\hline Vascular & Male & Frank & $\begin{array}{l}\text { Registered staff } \\
\text { nurse }\end{array}$ & 4 & 2 years \\
\hline Coronary care & female & Hannah & $\begin{array}{l}\text { Registered staff } \\
\text { nurse }\end{array}$ & Not known & Not known \\
\hline Male general medicine, cardiology \& diabetes & Male & Ian & $\begin{array}{l}\text { Registered staff } \\
\text { nurse }\end{array}$ & 5 & 1 years \\
\hline Male respiratory & Female & Kirsty & $\begin{array}{l}\text { Registered staff } \\
\text { nurse }\end{array}$ & 32 & 5 years \\
\hline Male respiratory & Female & Olga & $\begin{array}{l}\text { Registered senior } \\
\text { staff nurse }\end{array}$ & 9 & 9 years \\
\hline Male medicine, cardiology \& diabetes & Female & Pauline & $\begin{array}{l}\text { Registered senior } \\
\text { staff nurse }\end{array}$ & 14 & 12 years \\
\hline Female general medical & Female & Yolanda & $\begin{array}{l}\text { Registered staff } \\
\text { nurse }\end{array}$ & 1 & 1 month \\
\hline Female general medicine, cardiology \& diabetes & Female & Andrea & $\begin{array}{l}\text { Registered senior } \\
\text { staff nurse }\end{array}$ & 23 & 16 years \\
\hline
\end{tabular}

The total number of interactions recorded between patients and nurses was 47. The longest interaction lasted 24 minutes and 33 seconds and was related to a wound drain removal. The shortest interaction lasted 10 seconds and was related to personal care.

In relation to patients and nurses receiving sufficient information, two main themes emerged: sufficiency of information; and, insufficient information exchange. However, when using the data collected to test the theory of information exchange, other insights became evident, and were related to the intentions behind the information provided or exchanged. The findings related to sufficiency, insufficiency and the intentions related to the information, are presented.

\subsection{Sufficiency of information}


Patients and nurses stated that they had given and received sufficient information. Participants perceived that sufficient information had been exchanged because: information had been shared previously by other health professionals; they had no further questions; patients perceived that good relationships with nurses equated to enough information; and information was perceived as sufficient if the nurse spoke in lay terms.

\subsubsection{Information exchanged previously}

There was evidence of information being shared previously in the majority of cases. Some participants stated that sharing information occurred as an on-going process, for example:

We had the same conversations as I do every drug round, just to ensure that she knows what she's on and that we're giving her the correct information

$$
\text { [Carol, nurse, Case 11] }
$$

and:

Yeah, [l get information at] various times of day, and, more or less all day really, you know...

$$
\text { [Tracy, patient, Case 19] }
$$

Sometimes patients already knew the information that nurses were sharing, perhaps due to having a long-term condition, or a lengthy hospital stay. These patients had previously received information about their condition from their GP or specialist nurse, and were expert in their own conditions:

I know the process... I normally take my own [blood sugar

levels]; I take my own blood sugars when I'm at home. I inject

myself. But I know it all, I know what l've got to do...

[Colin, patient, Case 3]

Nurses commented that information was shared with patients at various times and in a range of circumstances, see Box 1.

\section{Box 1: Examples of information shared previously}

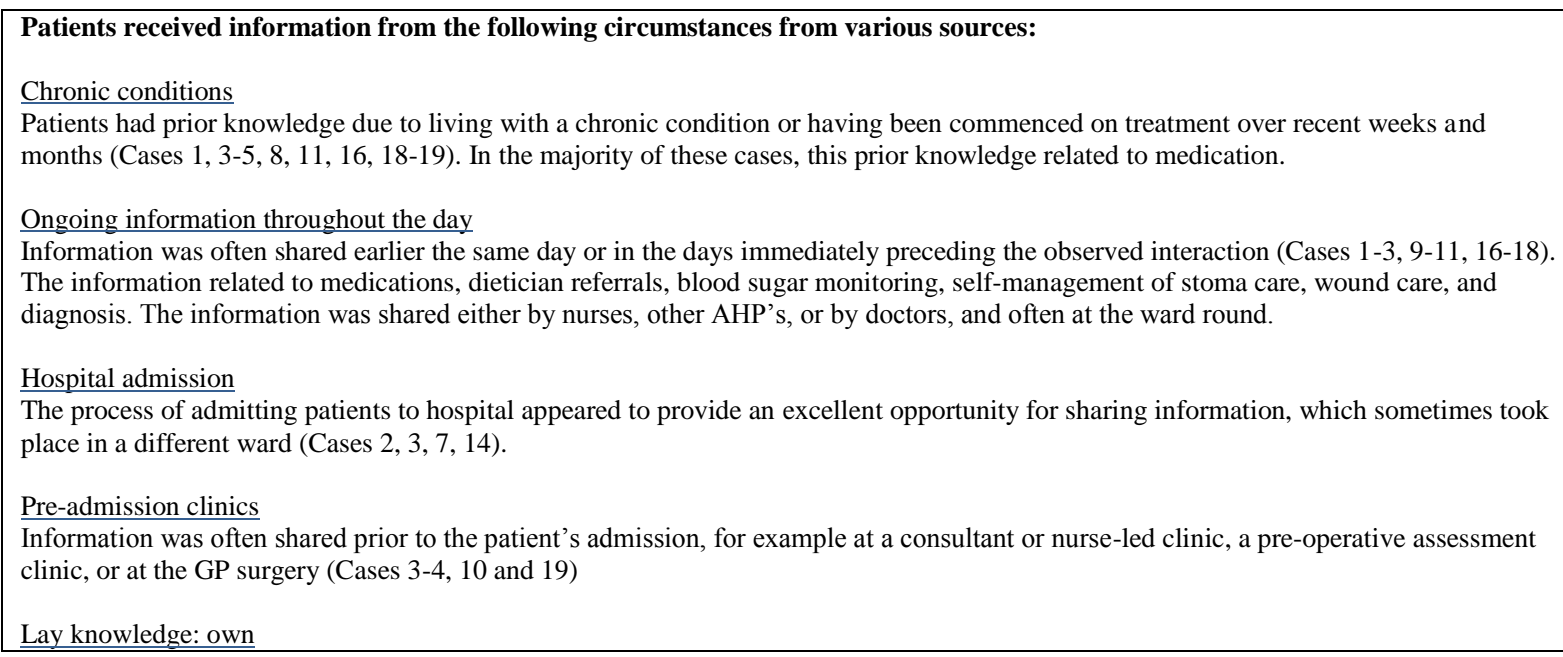


Patients had prior knowledge of treatments and procedures based on their own previous experience of the same or similar treatments or procedures (Cases 3 and 19). Their experiences related to drain removal, and episodes of pain for which strong painkillers were administered.

One patient had previously received anecdotal information about urinary catheter removal from his neighbour (Case 4). However, the information received led the patient to perceive that catheter removal was painful and may induce a shock reaction. The nurse attempted to reassure him but the patient remained anxious.

\subsubsection{Asking questions}

Most nurses perceived that patients had received 'enough' information when they stopped asking questions. Similarly, patients stated that if they wanted more information they would ask. Some patients ask many questions, whilst others do not, instead, as one nurse stated, they 'just take the information on' (Case 10). Some nurses stated that anxious patients, and younger patients, asked more questions (Cases 17-18). Older patients tended to ask questions of the nurse after the ward rounds, whereas younger patients, as stated by a nurse, 'just ask the doctor' (Case 18). Patients not asking further questions fostered a perception of having sufficient information among nurses.

\subsubsection{Therapeutic relationships}

Some nurses made it their aim to be approachable, which may facilitate information exchange as patient/nurse relationships develop:

We have an understanding of each other's lives and I think that does help when you have to go, and the news that you have to tell the patient isn't as good as they expected... But it does help because...this isn't some random professional who has come to say you have this, that or the other wrong. This is somebody that l've built up an understanding of...

[Oliver, nurse, case 9]

Patients trust the nurses to give them appropriate treatment and care, and to tell them the truth:

I think you're at ease with the person and if they're telling you something, it's about you...I trust the nurses to tell me the truth...

$$
\text { [Iris, patient, Case 9] }
$$

In a number of cases patients and nurses stated that they 'know' each other, sometimes 'quite well', and indeed that a 'friendship' had developed, irrespective of how long ago they met one another:

l've got quite close to some of them [nurses]...There's a

friendship and all that. It's amazing.

and:

[Kirsty, patient, Case 11]

I looked after him yesterday. I know him quite well.

[Duncan, nurse, Case 2]

Non-clinical or socially-based information was perceived by participants to develop therapeutic relationships, and thus facilitate information exchange. For example, some perceived that social communication helps to pave the way for Crispin et al. (2016) 
talking about 'bigger things', for example something sensitive, embarrassing or distressing (Cases 3, 5 and 17). Other participants perceived that banter and social conversation helps patients 'open up' and prevents patients from becoming 'standoffish' (Case 18).

\subsubsection{Layperson's terms}

Patients reported that most nurses used terms that they easily understood.

Patients preferred to hear information in 'plain English' (Cases 1-3 and 9-10) suggesting that speaking in lay terms facilitates information exchange. Some nurses reported that a significant part of their job was to talk to patients on their level, and one of the ways they achieve this is by not using jargon. One nurse described himself as a communication link between patients and doctors:

I think from a nursing perspective, we seem to be the communication bridge between medical staff and patients because doctors do tend to be very clinical and at times talk over the top of the patient.

$$
\text { [Oliver, nurse, Case 9] }
$$

Patients and nurses in this study perceived that they had given and received sufficient information. Sufficiency of information exchange was based on participants citing at interview that information shared previously, patients and nurses asking and answering questions, therapeutic patient/nurse relationships, and nurses speaking in layperson's terms meant that that they had received enough information. Despite this perception of sufficient information exchange, much of the observational data seemed to suggest that information exchange was not sufficient.

\subsection{Insufficient information exchange}

Despite participants stating that they had given and received sufficient information, analysis of the observational data indicated that information was provided but seldom exchanged. Charles et al. (1999) describe this as paternalistic information exchange. For example, one-way conversations were often observed, with nurses passing on information rather than engaging patients in a two-way conversation. Providing insufficient information may be due to: lost opportunities for sharing information; issues of power and control; and information being withheld. The observational data relating to these categories were followed up in the interviews.

\subsubsection{Lost opportunities}

A key finding in this study is that opportunities for sharing information were lost. Lost opportunities were evidenced by interruptions and the demands of the nurse's job. Interruptions during patient/nurse interactions were observed across all cases, and were made by other patients, other members of staff, and a nurse's pager. Interruptions resulted in the nurse changing the subject (Case 9), interactions being terminated (Cases 5, 7, 11 and 15), or the nurse assuming what the patient wanted to say (Case 8).

Interruptions were perceived by most nurses as inevitable, yet frustrating. Interruptions take up time in an already busy day and can negatively affect the amount of information exchanged. The following excerpt illustrates nurses' perceptions of interruptions as being problematic and frustrating: 
I'm used to it [interruptions] now. Just can be bugging that you cannot get on with something sometimes because somebody's asking you something or somebody wants you.

[Andrea, nurse, Case 15]

For some patients, interruptions highlighted a lack of privacy, which may be a more important issue than the information exchange itself:

Sometimes there's got to be a divide between having the chitchat [inclusive of other patients] and having a one to one with the nurse where it is just between you. It's just the setting you're in; it's lack of privacy.

[Rose, patient, Case 17]

Nurses often had no time to go back to patients with information later in the day often because of work responsibilities and demands on nurses' time. Some patients considered that the occupational demands on nurses were both problematic and a hindrance to sufficient information being shared:

l've known some nurses to go away and forget to come back (laughs). They get caught up in other things, you know, which I suppose it's not their fault either, cos they are so busy...

[Grace, patient, Case7]

Others commented that nurses cannot spend a long time treating each patient:

They're taught to take care of the patient, but they're taking care of him, they're taking care of me, somebody else doon [down] there, you know, they cannae [cannot] be everywhere...

[Larry, patient, Case 12]

Most nurses perceived the demands of their job as a hindrance to information exchange. Nurses felt that patients would hold back asking questions if they perceived that the nurse was busy and that nurses' busyness may cause patients to feel ignored (Cases 1 and 4). Nurses felt unable to spend necessary time with patients who had received bad news, or they could not get an opportunity to get back to the patient with information (Cases 3, 7, 14 and 17). One nurse described avoiding patients when faced with distressing conversations, partly because they do not have the time to spend with the patient:

They've [patients] just been given bad news, you're away giving out the dinners, giving out drugs, you've got no time to spend with them [patients] so it's just, it's horrendous, it's a shame, I feel really bad sometimes...I know if I go over and say 'how are you?' I'm going to be caught there for ten minutes or fifteen minutes, and l've got this, this, this to do...I think at times you avoid, you avoid patients or you avoid your room [patient bay] until you get this this this done.

[Queenie, nurse, Case 3]

\subsubsection{Power and control}

Data associated with power and control was related to nurses' use of paternalistic language. Some nurses' choice of words and use of abbreviations had 
the potential to exclude patients from conversations, make patients compliant, or keep them passive. Examples of paternalistic language use are presented in Box 2 . Nurses initiated interactions with phrases like 'What I'm going to do is...' and throughout interactions about care management nurses used phrases such as, 'the best thing for you is...' The following observational data extract from a nurse in response to a patient's question about future treatment, illustrates paternalistic language that potentially results in insufficient information being exchanged:

Look, this is what was said [at the ward round] and that's what's going to happen.

[Duncan, nurse, Case 2]

\section{Box 2: Examples of paternalistic language}

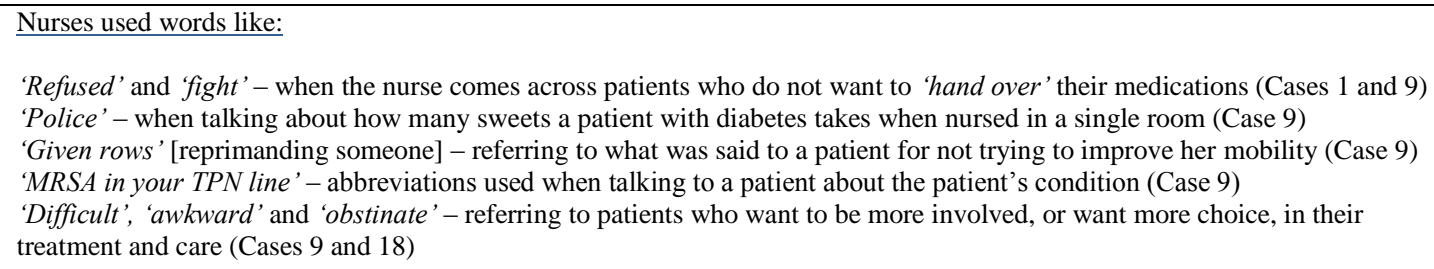

'Refused' and 'fight' - when the nurse comes across patients who do not want to 'hand over' their medications (Cases 1 and 9) 'Police' - when talking about how many sweets a patient with diabetes takes when nursed in a single room (Case 9)

'Given rows' [reprimanding someone] - referring to what was said to a patient for not trying to improve her mobility (Case 9) 'MRSA in your TPN line' - abbreviations used when talking to a patient about the patient's condition (Case 9)

'Difficult', 'awkward' and 'obstinate' - referring to patients who want to be more involved, or want more choice, in their

treatment and care (Cases 9 and 18)

Other observational data related to power and control were that nurses sometimes limited patients' choices. For example, nurses did not involve patients in decision-making, and when asked about this at interview, most of the evidence related to nurses considering that patients had had enough information. As examples, 'That's what information he needs just now' (Case 3), and, 'I just felt, that's enough information for her just now' (Case 11). Some patients also noticed that they were not involved in decision-making. For example, the patient in Case 4 stated that:

They always ask you nicely, but they go ahead anyway.

[Donald, patient, Case 4]

When nurses were asked at interview about involving patients and giving them choices, the issue of patient compliance emerged. Nurses stated they would document that patients 'refused' to give their medications to the nurse on admission: I would just document that [the patient] 'refused' and the minute they see 'refused' getting written, 'Oh no! Have them [the medications], just have them!'

[Helen, nurse, Case 1]

The use of the word 'refused' had the effect of patients complying with what was being asked.

Where issues of power and control were evident, there was the potential for paternalistic practice to occur without the nurse's knowledge - in other words, nurses may not have meant to exert power and control over patients. However, withholding information was perhaps more deliberate.

\subsubsection{Information withheld}

Sometimes information was withheld from patients. Explanations that nurses gave for withholding information varied. Some focussed on the effect that sharing more information might have on patients. Others were more focussed on what 
sharing the information meant for the nurse. Two overarching justifications for not sharing information related to nurses trying to 'protect' patients, and nurses wanting patients to comply with treatment.

One nurse, when asked at interview why she did not give the patient all of the information about his newly prescribed antibiotic, stated that she did not tell him of the risks because 'He might talk himself into having diarrhoea' (Case 4). The nurse went on to say that she withheld this information so that the patient would comply with treatment.

Patients withheld information about emotional concerns, and future intentions. For example, one patient told the nurse that she did not mind being transferred to another ward as she had been a patient in that other ward previously. However, when asked at interview how she felt about moving to another ward, the patient stated that she felt 'very depressed'. Furthermore, she stated that she felt depressed because 'you don't know where you're going', despite observational data showing that the patient told the nurse, 'I've been in that one [ward] before' (Case 8).

Another patient withheld information from the nurse about his likelihood of continued smoking, even while still an inpatient. He became unwell after smoking a cigarette post-surgery. The nurse, advised him against leaving the ward for a cigarette. However, the patient stated at interview that he had no intention of stopping smoking, that he had heard health promotion advice before, and that as well as being addicted, he enjoyed smoking.

\subsection{The intentions of the information}

As data analysis progressed, it was clear that patient/nurse interactions could not be reduced to a priori codes, but were far more complex. Many patient/nurse interactions in this study contained information that was related to patient well-being, socialisation, ethical and values-based practice, and nursing assessments.

One nurse reported that patients 'want to feel safe and feel happy under your care' (Case 11). Patients also like to know that nurses are concerned for their wellbeing:

Social interactions are quite important because it lets you understand that the nurses are... taking an interest in not only your well-being in hospital, but your wellbeing as a person.

[Neil, patient, Case 14]

Well-being was related to being able to cope. Patients sought diversions and distractions from their conditions to help them to cope whilst in hospital, for example:

Patient: [It's important to have a laugh] because it makes everything a wee bit easier to cope with.

[Kirsty, patient, Case 11]

Nurses stated that they needed to 'keep things quite jovial' (Case 12) or to 'have a wee joke' (Case 13) because they considered that the ward was a depressing environment for patients.

Some of the intent behind patient/nurse interactions is that of keeping things normal. Banter, humour and rapport all play an important part in helping patients 
maintain a sense of normality. Normality is also related to being perceived as a person and not a number:

You feel as if people [health professionals] are taking an interest, that you're not just a number.

[Grace, patient, Case 7]

One patient described interactions involving banter, humour and rapport as making a connection between himself and the nursing staff:

You can latch onto something. I think they [nurses]

connect with you if you connect with them. It's just

normal social interaction.

[Donald, patient, Case 4]

Some data suggested that giving information to patients is a hallmark of ethical practice, and is prerequisite to obtaining informed consent. Participants in this study reported informed consent and ethical practice in terms of patients' rights and obligations:

I think I've got a right to know what medication I'm taking...

and:

$$
\text { [Rose, patient, Case 17] }
$$

Ultimately you are ethically kind of obliged to keep them [patients] up to date...if he is asking me questions, you are kind of obliged to give him honest answers.

[Frank, nurse, Case 5]

One nurse who spoke about giving patients the information they need for informed consent, stated:

As long as she's [patient] got all the facts, we'll leave it at that. Obviously you need her permission for no matter which expert you want to come and have a look at her (laughs). But I would have coaxed her.

[Carol, nurse, Case 11]

Despite having stated that she would have needed the patient's consent when referring her to another care professional, the nurse spoke of 'coaxing' the patient, rather than engaging in decision-making with the patient.

Nurses used information to assess patients' immediate care needs and to plan future care:

When I'm writing up I'll probably write something like 'tired and lethargic' and I would document about her bowels because she is on Morphine.

[Andrea, nurse, Case 15]

Nurses used almost all information from patients to build a clinical picture for planning care:

Well we knew that he'd had a vasovagal episode this morning. His blood pressure had dropped and the headache was probably a knock-on effect from that. But 
we'd seen throughout the day that he was improving and his obs [vital signs] were checked again and they were better. So I thought, we'll see how his headache goes with Paracetamol

[Kate, nurse, Case 4]

\section{Discussion}

This paper presents patients' and nurses' perceptions, and observations of patient/nurse interactions, related to sufficiency of information exchange during routine nursing care.

\subsection{Significance of this study}

A key finding was the dichotomy between the interview data and the observational data. At interview, participants perceived they had given and received sufficient information. However, the observational data highlighted areas where, in comparison with the Charles et al. (1999) model of shared information exchange, information exchange was found wanting.

This key finding is important for two reasons. First, most policy documents, and best practice statements in the UK advocate shared decision-making, part of which is information exchange. They perceive shared decision-making and information exchange as: shifting the relationship between patient and professional towards a more shared approach (Coulter and Collins 2011); significant for helping patients take part in making care decisions (The Scottish Government 2010); an ethical imperative (Francis 2013); mutually beneficial for patients and healthcare staff (The Scottish Government 2007); and, something that patients aspire to be more involved in (Long-term Conditions Alliance Scotland 2008). However, these generic beneficial impacts of shared decision-making, and thus information exchange, are based on research that has not been undertaken in ward environments. Importantly, not being context specific can lead to patients in wards not receiving the information they need, and nurses feeling frustrated at not being able to reach the standards that policy sets. Second, patients and nurses receiving sufficient information in interactions during routine nursing care can potentially impact on patient health outcomes, particularly as the literature demonstrates in other contexts that having sufficient information can lead to positive health outcomes. Understanding sufficiency of information in ward settings is extremely important as in-patient health outcomes may be very different from those of out-patients at clinics and in doctors' surgeries.

\subsection{Discussion}

The findings indicate four explanations for patients' own perceptions of sufficiency of information, which are: information being shared previously; patients and nurses asking questions; therapeutic patient/nurse relationships; and, nurses speaking in lay terms. Patient/nurse interactions in ward settings take place on an ongoing basis with information being reiterated to patients over several days. Bugge et al. (2006) report that missing information may not be problematic in a particular interaction as the information may have been shared previously. Potentially, in ward settings, sufficiency is achieved through a cumulative effect of ongoing information exchange or provision. 
The link between knowledge and asking questions is not new (Graesser et al. 1993; Ram 1991). Shay and Lafata (2014) note the importance of patients asking questions, as patients reported a need for self-advocacy in order to take more involvement in shared decision-making. One fundamental difficulty with determining sufficient information by the questions patients ask is that patients may not know which questions to ask. However, this dilemma did not appear to be important for the majority of participants in our study.

Trust may be an important factor in deepening the patient/nurse relationship, which may facilitate information exchange further. Concepts such as approachability, trust, and 'knowing you' are new in terms of sufficiency in information exchange, and contribute to the literature that reports that good communication and rapport are important for positive health outcomes (Cole and McLean 2003; Connors et al. 1997). This study contrasts with other literature which suggests that good patient $\backslash$ nurse relationships may result in less information being shared (Thompson 2007).

Nurses speaking in lay terms enhanced patients' perceptions of receiving sufficient information, perhaps because the information shared has been understood. However, there is the potential for 'easily understood' information to be perceived as 'sufficient' information. Difficulties with jargon are well documented: jargon distances patients from health professionals; can be used to exert control; and increases dissatisfaction with the information received (Fields et al. 2008; Liu et al. 2013; Simon et al. 2013).

An important factor in patient/nurse interactions is that they cannot be reduced to concepts like information exchange. There is the potential to be seduced by the theory of information exchange for shared decision-making, when potentially its applicability may be limited. When the data collected is used to test the theory, much more than the theory emerges, including intentions and expectations of interactions, like patient well-being, socialisation, ethical and values-based practice, and nursing assessments. These areas of patient/nurse interactions are part of nurses' emotion work with patients, demonstrating compassion (Msiska et al. 2014), helping to relieve anxieties (Costa 2001; Inman et al. 2013), and helping patients maintain a sense of normality in an unfamiliar environment (Hughes 2010). Redsell et al. (2007) state that patients prefer to see doctors about clinical symptoms, and to see nurses for reassurance. Patients may not be looking for decision-making to be part of the agenda for patient/nurse interactions any more than they may be looking for the GP consultation agenda to include friendly banter.

In our study, participants perceived they had received sufficient information, despite the observational data highlighting where information was not being exchanged. The data in this study can be linked to historical literature suggesting that patients do not like to say negative things about nurses caring for them (Taylor 1979; Waterworth and Luker 1990). Some important findings in this study were that there were lost opportunities for sharing information, issues of power and control, and information being withheld, which potentially prevented sufficient information being exchanged. These findings have implications for practice in terms of nurses finding a way to reduce the amount of interruptions to their interactions with patients, and of nurses relinquishing power. However, issues such as interruptions and nurses relinquishing power go beyond information exchange for shared decision-making. They are fundamental communication issues that have practical implications at the most basic level. This study's observation data links with some already known 
barriers to patient involvement and decision-making in clinic or GP settings. These barriers are reported to be difficulties with the concept of patient involvement (Forbat et al. 2009); shared decision-making being time consuming (Arnetz et al. 2008); pressurising an already strained workload (Friedberg et al. 2013); and lack of training on sharing information (Friedberg et al. 2013). Participants perceiving they had given and received sufficient information is new knowledge, and lies in contrast to what others have reported (Ford et al. 2003; Frongillo et al. 2013; Isaacs et al. 2013; Selman et al. 2009; Suhonen and Leino-Kilpi 2006).

The findings of this study provide a foundation for exploring information exchange in ward settings further. Recommendations such as: nurses encouraging patients' contributions to sharing information by using higher-level communication and listening skills; nurses being aware of language use, and issues of power and control; and nurses not being evasive in sharing information, can only be tentatively linked to information exchange for shared decision-making. More research is needed to establish the applicability of the theory of information exchange to nursing practice in ward settings.

Current UK policies on shared decision-making and information exchange are not context specific but imply homogeneity across all areas of healthcare. However, a 'one-size-fits-all' policy might not consider the practicalities of fast-paced ward environments that often constrain patient/nurse interactions. Policymakers could take account of the needs of varying healthcare contexts, for example workforce planning, nursing skill mix and named nurses for patients, and create policies that are targeted effectively across a range of significantly different environments. A change in policy, accounting for these needs, might empower patients in their interactions with nurses rather than set nurses up to fail against policies that are non-specific in terms of context. However, recommending changes to policy from the findings here alone would be remiss, as the generalisability of the findings is difficult to establish due to the complexities of patient/nurse interactions and the need for more research.

\subsection{Merits and limitations}

Sufficiency of information in ward settings has not previously been reported in the literature. Being a qualitative multiple-case study with 19 cases, the study was large in terms of case study design. Therefore, some transferability can be made to similar contexts. The strong study design and the innovative data collection method elicited real-time data to capture in-depth accounts of participants' perceptions of the sufficiency of information shared or provided.

Rigour was achieved at each stage of data analysis. Using Miles et al. (2013) process of data analysis helped to bring focus to the data, organise it to an accessible form and draw valid conclusions. Data analysis was iterative therefore the methods for achieving rigour were also iterative and included: concurrent data collection and analysis; triangulation; use of extensive field notes; peer debriefing; use of a software programme for data management and coding; exploring data within and across cases; appraising new insights against current literature; and being challenged by peers to look for alternative interpretations of the data.

Research and discussion on information exchange often miss the complexity linked to the importance of the information in terms of intentions behind the information and their relevance to patients and nurses. Undertaking this study in ward settings with patients and nurses may have helped to illuminate these complexities. 
Conflicting data were found between the interview and observation data. However, this dichotomy strengthened the data analysis due to triangulation between the observation, field note and interview data. The dichotomy provided conflicting perceptions that needed further exploration.

Caution should be taken regarding the weight given to the interview and observation data. Using an a priori theory has its challenges: the researcher can be so absorbed in the theory and therefore miss important aspects of patient/nurse interactions during observation; and at interview there always remains the potential that participants might contradict themselves (Barbour, 2008). Explaining the dichotomy between the interview and observation data might depend on what weight was given to either data set. To help combat this favouring between interview and observation data, field notes included a reflexive journal where the researcher could thoughtfully consider the data collected and note any biases. The dichotomy would need to be corroborated, or disputed by further research before the interpretation of these findings could be generalized.

The observation sessions were limited to ninety minutes each, resulting in 'snapshot' data collection, which may have had a bearing on some of the core findings. However, 47 patient/nurse interactions were observed, helping to address this limitation. Unobtrusive research methods were used and the wards were visited regularly by the first author in an attempt to have the potential participants get used to her presence, therefore limiting any Hawthorne effect.

\section{Conclusion}

Patients and nurses perceived that the information they received was sufficient. However, information exchange, as it is defined in the literature, was generally not achieved between the participants in this study. The observed insufficiency of information was in part due to lost opportunities. Much more needs to be learned about information exchange and sufficiency of information in patient/nurse interactions in ward settings. If further research indicates that the currently prescribed information exchange (Charles et al 1999) is not the right fit for the ward environment, then perhaps policymakers can find a new way to ensure that patients get sufficient information to make healthcare decisions whilst in the ward setting.

\section{Conflict of interest}

None declared.

\section{Funding}

The project was funded by University of Stirling as a PhD project. This research did not receive any specific grant from funding agencies in the public, commercial, or not-for-profit sectors.

\section{Ethical approval}

Ethical approval was obtained from the National Health Service West of Scotland Research Ethics Committee (REC NO. 09/S0704/26) 


\section{Acknowledgements}

Our thanks go to the patients and staff at the teaching hospital where the research was undertaken. Our thanks also go to the University of Stirling for sponsoring and funding this PhD.

\section{References}

Arnetz, J., Winblad, U., Arnetz, B., Hoglund, A. (2008) Physicians' and nurses' perceptions of patient involvement in myocardial infarction care. Eur. J. Cardiovasc. Nur. 7 113-20.

Barbour, B. (2008) Introducing qualitative research: a student guide to the craft of doing qualitative research. SAGE Publications, London

Bugge, C., Entwistle, V., Watt, I. (2006) The significance for decision-making of information that is not exchanged by patients and health professionals during consultations. Soc. Sci. Med. 63 2065-78.

Butler, M., Treacy, M., Scott, A., Hyde, A., MacNeela, P., Irving, K., et al. (2006) Towards a nursing minimum data set for Ireland: making Irish nursing visible. J. Adv. Nurs. 55 364-75.

Charles, C., Gafni, A., Whelan, T. (1999) Decision-making in the physician-patient encounter: Revisiting the shared treatment decision-making model. Soc. Sci. Med. $49651-61$.

Cole, M., McLean, V. (2003) Therapeutic relationships re-defined. Occup. Therap. Men. Health. 19 33-56.

Connors, G., Carroll, K., Di Clemente, C., Longabaugh, R., Donovan, D. (1997) The therapeutic alliance and its relationship to alcoholism treatment participation and outcome. J. Consultan. Clin. Psych. 65 588-98.

Costa, M. (2001) The lived perioperative experience of ambulatory surgery patients. Assoc. of Periop. Reg. Nurs. J. 74 874-881

Coulter, A., Collins, A. (2011) Making shared decision-making a reality: no decision about me, without me. London; The Kings Fund

Cresswell, J. (2013) Qualitative inquiry and research design: choosing among five approaches, third ed., SAGE Publications, London.

Crispin, V. (unpublished results) Information exchange between patients and nurses during routine nursing care in ward settings: a qualitative multiple-case study [unpublished thesis]

Data Protection Act (1998) Data Protection Act. London; The Stationery Office 
Doherty, C., Doherty, W. (2005) Patients' preferences for involvement in clinical decision-making within secondary care and the factors that influence their preferences. J. Nurs. Man. 13 119-27.

Duncan, C,. Best, C., Hagen, S. (2010) Shared decision making interventions for people with mental health conditions. Cochrane DB. Syst. Rev. 1 CD007297.

Edwards, A., Elwyn, G. (2004) Involving patients in decision making and communicating risk: a longitudinal evaluation of doctors attitudes and confidence during a ransomized trial. J. Eval. Clin. Pract. 10 431-7.

Entwistle, V., Williams, B., Skea, Z., Maclennan, G., and Bhattacharya S. (2006) Which surgical decisions should patients participate in? Reflections on women's recollections of discussions about different types of hysterectomy. Soc. Sci. Med. 62 499-509.

Fielding, F., Fielding, J. (1986) Linking data, SAGE Publications, Beverley Hills.

Fields, A., Freiberg, C., Fickenscher, A., Shelley, K. (2008) Patients and jargon: Are we speaking the same language? J. Clin. Anaesth. 20 343-6.

Forbat, L., Hubbard, G., Kearney, N. (2009) Patient and public involvement: models and muddles. J. Clin. Nurs. 18 2547-54.

Ford, S., Schofield, T., Hope, T. (2003) Are patients' decison-making preferences being met? Health Expect. 6 72-80.

Francis, R. (2013) Report of the Mid Staffordshire NHS Foundation Trust Public Inquiry: executive summary. London: The Stationery Office.

Friedberg, M., Van Busum, K., Wexler, R., Bowen, M., Schneider, E. (2013) A demonstration of shared decision making in primary care highlights barriers to adoption and potential remedies. Health Affair. 32 268-75.

Frongillo, M., Feibelmann, S., Belkora, J., Lee, C., Sepucha, K. (2013) Is there shared decision-making when the provider makes a recommendation? Patient. Edu. Couns. 90 (2013) 69-73.

Goossen, W., Epping, P., Van Den Heuvel, W., Feuth, T., Frederiks, C., Hasman, A. (2000) Development of the Nursing Minimum Data Set for the Netherlands (NMDSN): identification of categories and items. J. Adv. Nurs. 31 536-47.

Graesser, A., Langston, M., Baggette, W. (1993) Exploring information about concepts by asking questions, in: G. Nakamura, D. Medin, R. Tarabin (Eds.), Categorization by humans and machines, Academic Press, San Diego, pp. 411-36.

Holloway, I., Wheeler, S. (2010) Qualitative research in nursing and healthcare, third ed., Wiley-Blackwell, Oxford. 
Hughes, C. (2010) Laparoscopic surgery for endometrial cancer: a phenomenological study. J. Adv. Nurs. 66 (11) 2500-2509

Inman, D., Jacobson, T.M., Maxon, P., Huey, W., Lohse, C. (2013) Effects of urinary catheter education for patients undergoing prostatectomy. Uro. Nurs. 33 (6) 289-298

Isaacs, C., Kistler, C., Hunold, K., Pereira, G., Buchbinder, M., and Weaver, M. et al. (2013) Shared decision-making in the selection of outpatient analgesics for older individuals in the emergency department. J. Am. Geriatrics Soc. 61 793-8.

Jacobs, V. (2000) Informational needs of surgical patients following discharge. Appl. Nurs. Res. 13 12-8.

Jones, A., Bugge, C. (2006) Improving understanding and rigour through triangulation: an exemplar based on patient participatient in interaction. J. Adv. Nurs. 55 612-21.

Joosten, E., DeFuentes-Merillas, L., De Weert, G., Sensky, T., Van Der Staak, C., De Jong, C. (2008) Systematic review of the effects of shared decision-making on patient satisfaction, treatment adherence and health status. Psychother. Psychosom. 77 219-26.

Lithner, M., Zilling, T. (2000) Pre- and postoperative information needs. Patient Edu. Couns. 40 29-37.

Liu, W., Manias, E., Gerdtz, M. (2013) Medication communication during ward rounds on medical wards: Power relations and spatial practices. Health. 17 113-34.

Logan, K., Shaw, C., Webber, I., Samuel, S., Broome, L. (2008) Patients' experiences of learning clean intermittent self-catheterization: A qualitative study. J. Adv. Nurs. 62 32-40.

Long-term Conditions Alliance Scotland. (2008) Gaun Yersel! The self management strategy for long term conditions in Scotland. Edinburgh; The Scottish Government

May, V., Clarke, T., Coulling, S., Cowie, L., Cox, R., Day, D., Husk, J., Laslett, S., Mansell, S., McHenry, M. (2006) What information patients require on graduated compression stockings. Brit. J. Nurs. 15 263-70.

Miles, M., Huberman, A., Saldana, J. (2013) Qualitative data analysis: A methods sourcebook, third ed., SAGE Publications, Thousand Oaks, California.

Msiska, G., Smith, P., Fawcett, T., Nyasulu, B. M. (2014) Emotional labour and compassionate care: what's the relationship? Nurs. Ed. Today 34 (9) 1246-1252.

Nelson, B., Kinjo, K., Meier, D., Ahmad, K., Morrison, R. (2005) When critical illness becomes chronic: informational needs of patients and families. J. Crit. Care. 20 7989. 
Ram, A. (1991) A theory of questions and question asking. J. Learn. Sci. 1 (3\&4) 273-318.

Redsell, S., Stokes, T., Jackson, C., Hastings, A., Baker, R. (2007) Patients' accounts of the differences in nurses' and general practitioners' roles in primary care. J. Adv. Nurs 57 (2) 172-180

Selman, L., Higginson, I., Agupio, G., Dinat, N., Downing, J., Gwyther, L., et al. (2009) Meeting information needs of patients with incurable progressive disease and their families in South Africa and Uganda: Multicentre qualitative study. Brit. Med. J. 338 1326-36

Shay, L., Lafata, J. (2014) Understanding patient perceptions of shared decision making. Patient Edu. Couns. 96 295-301.

Shih, F. (1998) Triangulation in nursing research: Issues of conceptual clarity and purpose. J. Adv. Nurs. 28 631-41.

Shortus, T., Kemp, L,, McKenzie, S., Harris, M. (2013) Managing patient involvement: provider perspectives on diabetes decision-making. Health Expect. 16 $189-98$.

Simon, M., Ragas, D., Nonzee, N., Phisuthikul, A., Luu, T., Dong, X. (2013) Percpetions of patient-provider communication in breast and cervical cancer-related care: A qualitative study of low-income English- and Spanish-speaking women. J. Comm. Health. 38 707-15.

Suhonen, R., H. Leino-Kilpi, H. (2006) Adult surgical patients and the information provided to them by nurses: A literature review. Patient Edu. Couns. 61 5-15.

Suhonen, R., Nenonen, H., Laukka, A., Valimaki, M. (2005) Patients' informational needs and information received do not correspond in hospital. J. of Clin. Nurs. 14 1167-76

Taylor, S. (1979) Hospital patient behaviour: reactance, helplessness, or control? J. Soc Issues 35 156-184

The Scottish Government. (2010) The healthcare quality strategy for NHSScotland. Edinburgh; The Scottish Governement

The Scottish Government. (2007) Better health; better care: action plan. Edinburgh; The Scottish Government

Thompson, A. (2007) The meaning of patient involvement and participation in health care consultations: A taxonomy. Soc. Sci. Med. 64 1297-310.

Van Den Brink-Muinen, A., Van Dulmen, S., De Haes, H., Visser, A., Schellevis, F., and Bensing, J. (2006) Has patients' involvement in the decision-making process changed over time? Health Expect. 9 333-42.

Crispin et al. (2016) 
Waterworth, S., Luker, K. (1990) Reluctant collaborators: do patients want to be involved in decisions concerning their care? JAN 15 971-976

Werley, H., Devine, E., Zorn, C., Ryan, P., Westra, B. (1991) The Nursing Minimum Data Set: abstraction tool for standardized, comparable, essential data. Am. J. Public Health. 81 421-6.

Yin, R. (2014) Case study research: design and methods, SAGE Publications, Thousand Oaks, California. 